\title{
Comparison of ozonation removal for PPCPs in secondary treated sewage by microbubble generator and ejector
}

\author{
Ilho $\mathrm{Kim}^{1,2}$, Jaiyeop $\mathrm{Lee}^{1,2^{+}}$ \\ ${ }^{1}$ Urban Water Circulation Research Center, Korea Institute of Civil Engineering and Building Technology, Goyang 10223, Republic of Korea \\ ${ }^{2}$ Department of Construction Environment Engineering, University of Science and Technology, Daejeon 34113, Republic of Korea
}

\begin{abstract}
This study analyzed residues of PPCPs in secondary treated sewage water, and their amount eliminated by ozonation processes. A microbubble nozzle and ejector were used to dissolve ozone. To consider a low concentration of PPCPs, a SPE method was performed on samples prior to the analysis. The concentration of dissolved ozone was $4.00 \mathrm{mg} / \mathrm{L}$ in the microbubble and $2.49 \mathrm{mg} / \mathrm{L}$ in the ejector. To examine elimination trends, the experiment was also performed at a low concentration of ozone, 1/10 of its original concentration. The maximum elimination rate on average was $93.0 \%$ in the ejector, higher than that in the microbubble (90.1\%), but 16 PPCPs were found to show a relatively high elimination rate in the microbubble, higher than the ejector. Elimination trends with respect to time were distinguished based on inflection point, and 11 PPCPs were concentrated on the latter half of the microbubble after the inflection point at the low concentration of ozone, which was compared to other cases. In the source water, concentrations of 2 PPCPs were higher than the reference toxic concentration based on the QSAR model, but after treatment, only bezafibrate was over the value when the ejector with low ozone injection concentration was applied
\end{abstract}

Keywords: Ejector, Microbubble, Ozonation, PPCPs, Sewage secondary treated water

\section{Introduction}

Residues of pharmaceuticals and personal care products (referred to as "PPCPs") that are not sufficiently treated in sewage treatment plants have been reported not only in other countries but also in South Korea [1-3]. Effluents from sewage treatment plants flow into natural water systems, and despite the small amount of residues of PPCPs contained in the effluents, their continuous inflow can cause chronic toxicity to animals and plants in the ecosystem [4, 5].

Most compounds originating from pharmaceuticals and personal care products (PPCPs), such as Acetaminophen and Caffeine, which were covered in this research, are more than $90 \%$ removed in the water purification process [6, 7]. However, carbamazepine and sulfamethoxazole showed a relatively low removal rate of 78 to $84 \%$ when the inflow water concentration was low [7]. In the coagulation process, a removal rate of less than $50 \%$ was also shown for the coagulants of iron salts and aluminum salts $[7,8]$. In adsorption, there were removal rates of some $90 \%$ or more, but in large part the removal rate was unstable, ranging from 23 to $79 \%$. This suggests the need for the treatment of PPCPs flowing into sewage treatment plants [9, 10].

Processes such as advanced oxidation processes (AOPs) [2, 11-13] and membrane separation processes (MSPs) $[13,14]$ are used to remove the residues of PPCPs. Nanofiltration (NF) and reverse osmosis (RO) are used in the MSPs, but applying NF and RO to sewage treatment processes does not seem to be cost-effective or suitable for operation. Meanwhile, AOPs have been introduced to multiple sewage treatment processes, not for removing residues of PPCPs, but for other purposes such as disinfection.

Eduardo et al. [15] reviewed the removal of PPCPs through various AOP combined processes, and reported that antibiotics such as PPCPs were well-removed by the AOP processes. The AOP process is reported to achieve good removal of antibiotics materials such as PPCPs. In a single process of photodegrading, the antibiotics showed a removal rate of 60 to $100 \%$, and 99 to $100 \%$ when the $\mathrm{H}_{2} \mathrm{O}_{2}$ process was added. In the $\mathrm{TiO}_{2} / \mathrm{UV}$ oxidation process, the removal rate was between 88 and 100\%. The Fenton oxidation and Photo-Fenton process showed elimination rates of 40 to $100 \%$ and 79 to $100 \%$, respectively. The ozone $/ \mathrm{H}_{2} \mathrm{O}_{2}$ process showed a $92 \%$ to $100 \%$ elimination rate and the ozone $/ \mathrm{H}_{2} \mathrm{O}_{2} / \mathrm{UV}$ combination process showed
This is an Open Access article distributed under the terms of the Creative Commons Attribution Non-Commercial License (http://creativecommons.org/licenses/by-nc/3.0/) which permits unrestricted non-commercial use, distribution, and reproduction in any medium, provided the original work is properly cited.

Copyright (C) 2022 Korean Society of Environmental Engineers
Received March 30, 2020 Accepted February 02, 2021

${ }^{\dagger}$ Corresponding author

E-mail: pas2myth@kict.re.kr

Tel: +82-31-995-0878 Fax: +82-31-910-0291

ORCID: 0000-0002-4663-1890 
a 90 to 100\% elimination rate, excluding Penicillin G. Ozone processes alone had a processing rate of 55 to $100 \%$. However, the above AOP process is on a variety of matrixes, not sewage treatment water, and only provides indirect treatment trends due to different treatment conditions. The above AOP processes had been applied to remove PPCPs, but many studies reported that PPCPs were significantly removed by single ozonation processes [11].

For sewage sources, secondary treated water filtered through sand filtration showed that most PPCPs had a removal rate of more than $80 \%$, suggesting that they could be treated stably. However, some substances such as carbamazepine and ketoprofen showed an unstable elimination rate of less than 50\% [2].

Most earlier studies on ozonation did not suggest ozone injection methods separately [2, 12, 13], but most cases seem to use general dissolution methods like diffuser and ejector. Meanwhile, injection methods using microbubble dissolve ozone by pressurization, and they were reported to show a higher efficiency than other dissolution methods [16, 17].

The elimination rate of chemicals in treated water needs to be assessed not as an amount simply, but based on the concentration of chemicals that affects living things. The WHO and other overseas standards for PPCPs focus on highly toxic organic compounds such as herbicides [18]. Toxicity reports on PPCPs are presented based on exposure concentrations in drinking water sources and clinical permissible concentrations [19-21]. Diclofenac alone was adopted in Europe as acceptable under $100 \mathrm{ng} / \mathrm{L}$ [22].

The WHO has presented figures obtained by comparing exposure levels with reference exposure components based on acceptable daily intake (ADI) or minimal therapy dose (MTD) as margins of exposure (MOE) for risk assessment as guidelines for determining the concentration of human hazards [23]. It was also introduced that the concentration of PPCPs in drinking water is 1,000 times lower than this MTD. This number is the same as the AF (assessment factor) used to derive the predicted exposure concentration (PNEC) from the toxic concentration [24].

In the case of toxic substances, in particular, even if a slight amount is detected, their hazards differ by their toxicity. Toxicity information is available only for very few chemicals. To address the problem, a model called quantitative structure activity relationship (QSAR) was developed to estimate the overall hazards of chemicals and provide quantitative values [25, 26]. QSAR is a statistical model designed to estimate the hazards of chemicals by identifying their molecular structure of chemicals based on the toxicity of each functional group of chemicals. The concentration of concern (COC) [27], which is the value obtained based on the lowest value of chronic aquatic toxicity for fish, Daphnia magna and green algae by the QSA, and divided by 10 as an uncertainty factor, has been widely used when estimating chronic toxicity level of a certain compound. In this study, following WHO guidelines [23] the calculation of the reference toxic concentration was set to one-thousandth of the COC instead of MTD as a criterion for assessing drinking water risks, and monitored for reduction before and after ozone treatment.

Since treated sewage effluents contain other organic matters as well as residues of PPCPs, they show different trends from water purification or waste water treatment, and thus they have been relatively less researched. This study injected ozone through microbubble and examined the elimination trends of residues of PPCPs in secon- dary treated sewage water. Their treatment rate was compared, and the elimination trends of each PPCP depending on the concentration of injected ozone was analyzed based on the point of inflection and was compared with an ejector, the previous work [12]. In addition, the elimination status of residues of PPCPs in secondary treated sewage water before and after treatment was examined.

\section{Experimental Section}

\subsection{Microbubble Generator and Ejector}

The sewage water treated in this study was the secondary treated sewage water collected from a sewage treatment plant in Korea before it flows into the tertiary treatment process. The mean TOC value was $7.28 \mathrm{mg} / \mathrm{L}$ and the standard deviation was $0.15 \mathrm{mg} / \mathrm{L}$.

The scheme of the ozone dissolution set was as shown in Fig. S1. The set was designed to switch the ejector and microbubble nozzle simply by operating their valves. The amount of ozone generated by an ozone generator was $20 \mathrm{~g} / \mathrm{h}$, and the maximum gas concentration was $120 \mathrm{mg} / \mathrm{L}$. Microbubbles were generated through pressure drop by the microbubble generator when passing through a projected area within a nozzle. The microbubbles were mixed with ozone gas injected in the pipeline in the gas-liquid form. The same flow and mixture conditions as the microbubble generator were applied to the ejector.

The concentration of ozone gas and reaction time were set to have the optimal ratio of liquid flow velocity to ozone gas flow velocity. The flow velocity of liquid was $25 \mathrm{~L} / \mathrm{min}$, and the volume of the collected sewage water was $80 \mathrm{~L}$. The injected amount and time of ozone were set to maintain the concentration of ozone at 3-4 mg/L, known as effective in eliminating PPCPs [2, 6]. To compare the trend of elimination at low concentrations of ozone, one-tenth of the original ozone concentration was additionally experimented. The concentrations of ozone injected through the microbubble and ejector at the standard concentration (high) and the low concentration (low) along the experimental time were as shown in Fig. 1. The concentration of ozone dissolved by the ejector was $62.2-69.1 \%$ of that by the microbubble.

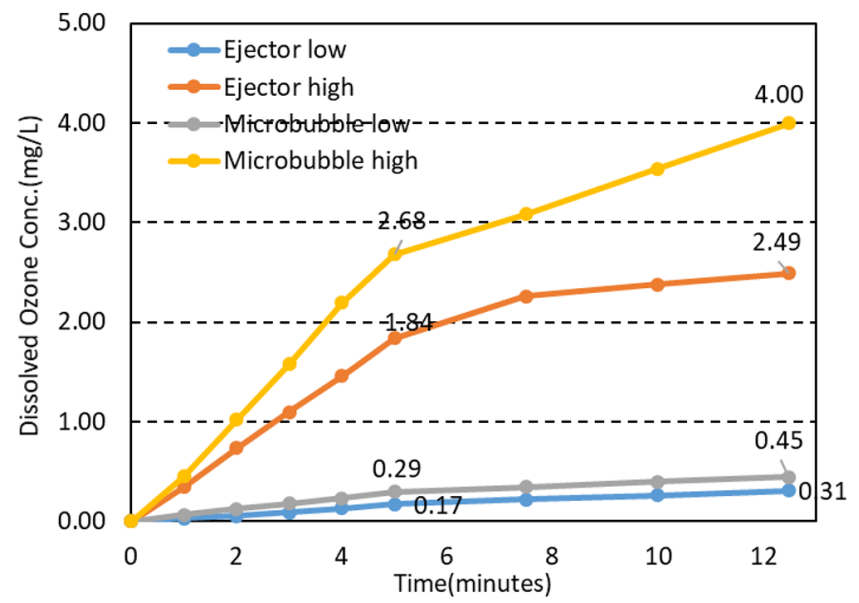

Fig. 1. The dissolved ozone concentration in ejector and microbubble with respect to time. 


\subsection{Analysis}

To extract the trace level of residual organic matters in samples, the samples were run through an Oasis HLB (Hydrophilic-Lipophilic Balance) extraction cartridge (6 cc/100 mg) and were fixed to solid phase. Before they were run through the extraction cartridge, the extraction cartridge was conditioned with $3 \mathrm{~mL}$ of methanol and $6 \mathrm{~mL}$ of ultrapure water. To exclude the addition reaction of metals on the samples, $1 \mathrm{~g} / \mathrm{L}$ of EDTA was added, and the samples were filtered with a Grade GF/B filter of $1 \mu \mathrm{m}$ pore size. After extraction, they were ventilated for $2 \mathrm{~h}$ for dehydration. The cartridge was eluted using $6 \mathrm{~mL}$ of methanol, and $\mathrm{N}_{2}$ purge was conducted on the eluted solution at $37^{\circ} \mathrm{C}$ and $0.3-0.4 \mathrm{~L} / \mathrm{min}$. The dried solution was dissolved again using $0.1 \%$ formic acid and methanol, and was analyzed using liquid chromatography with tandem mass spectrometry (LC/MS-MS). A total of 59 PPCPs were analyzed and classified by usage as shown in Table S1 with detailed QA/QC information. For simultaneous analysis, a gradient elution method [28] that changes the polarity of the mobile phase was used.

\section{Results and Discussion}

\subsection{Concentration and Biotoxicity of PPCPs after Secondary Treatment}

The average concentration of PPCPs in the secondary treated sewage water collected from a sewage treatment plant was listed in alphabetical order in Fig. 2. Out of 59 analysis targets, 26 PPCPs were detected and their average concentration was $30.6 \mathrm{ng} / \mathrm{L}$. The standard deviations of the PPCPs were arranged in Table S3 with the physicochemical information and their abbreviations.

The PPCPs that showed the highest concentration was sulpride (154.8 ng/L) and crotamiton (84.4 ng/L) used as antipsychotics and antipruritics, respectively, followed by lincomycin (68.6 ng/L) used as antibiotics, and bezafibrate (67.9 $\mathrm{ng} / \mathrm{L})$ used as antilipemics.

By usage, others that were grouped together due to a small number of PPCPs showed the highest concentration (48.2 ng/L), followed by antibiotics (38.8 ng/L), antimicrobials (29.9 ng/L), antipyretic analgesics (14.1 ng/L) and antiarrhythmics (6.8 ng/L).

To examine their hazards on living things, LC50 or EC50 suggested by a quantitative structure activity relationship (QSAR) model were estimated and compared with the detected concentration. The QSAR model used here was the module contained in the EPI SuiteTM v4.11 program produced in the United States (USEPA, 2012). The detected concentration of 26 target PPCPs in the secondary treated sewage water were compared the reference toxic concentrations in (Fig. 3). The reference toxic concentration was set as one-thousandth of COC as described above. The straight line crossing the graph is the criterion for separating each reference toxic concentration value of PPCPs. The toxic concentration of 2 PPCPs including bezafibrate and triclosan was 1.99-2.35 times higher than the reference toxic concentration, and that of mefenamic acid was 0.761 times, which was close to the criterion. A material safety data sheet (MSDS) has been already issued for the PPCPs individually, because their toxicity was proved and long-term exposure to them causes chronic toxicity. For the 3 PPCPs that surpassed the criterion including bezafibrate, their detected concentrations, ratio by minimum toxic concentration and toxicity information are listed in Table S2.

Since the concentration was measured after the secondary treatment, it is expected to be reduced to below the reference toxic concentration after the tertiary treatment and disinfection performed in general public sewage treatment plants. However, effluents from simple sewage treatment plants where only secondary treatment is applied are expected to hazard aquatic ecosystems with PPCPs. This also demonstrates the validity of introducing TOC (total organic carbon) water quality standards for non-biodegradable organics.

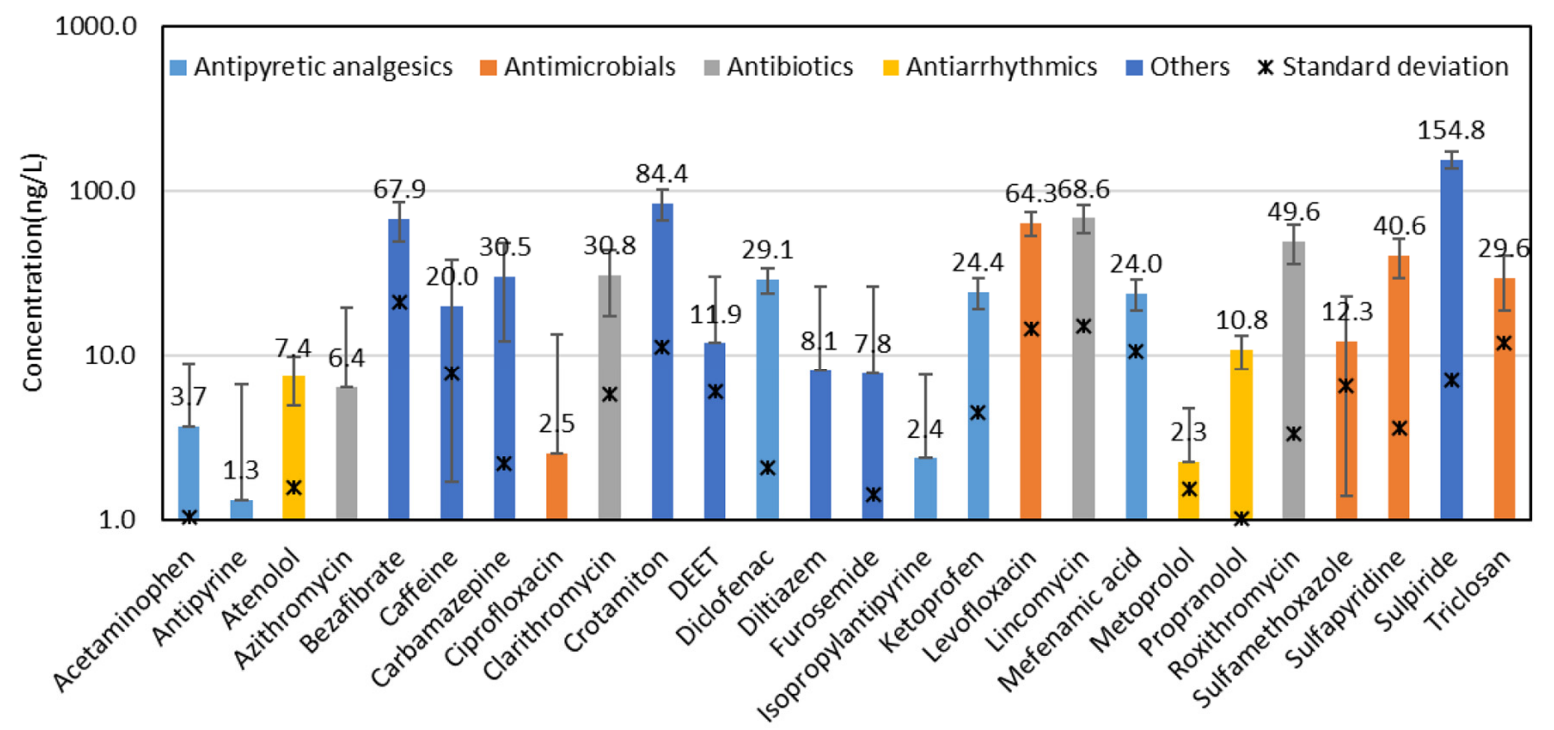

Fig. 2. PPCPs in 2ndary treated sewage water ( ${ }^{*}$ standard deviation). 


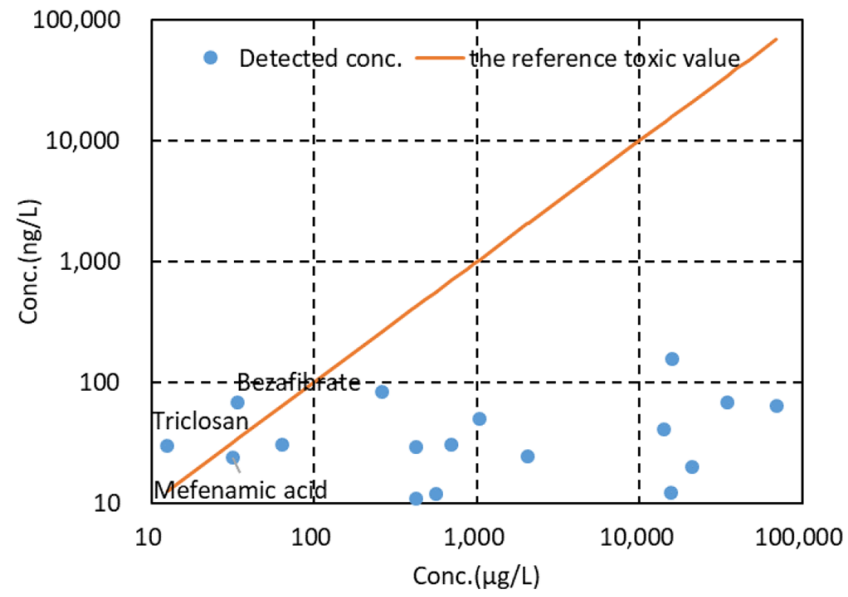

Fig. 3. Toxicity of PPCPs in 2ndary treated sewage water.

\subsection{Final Elimination Efficiency by Case}

A comparison of removal rates at low and high concentrations via two processes is shown in Fig. 4. The microbubble process averaged $63.2 \%$ removal at low concentrations, but this was increased to $90.7 \%$ at high concentrations. When the ejector process was used, the removal rate increased from $58.0 \%$ to $93.0 \%$. The PPCPs below average at low ozone concentrations in the microbubble process were acetaminophen, bezafibrate, clarithromycin, ketoprofen, lincomycin, metoprolol, propranolol, sulfamethoxazole and sulpiride, with an average elimination rate of $28.5 \%$. At high ozone concentrations, this was improved to an average of $83.5 \%$. However, the removal rates achieved using metoprolol and sulfamethoxazole were $49.7 \%$ and $66.5 \%$, respectively, which is far below the average. The above two substances were removed at rates of $91.7 \%$ and $98.4 \%$, respectively with a high concentration of the ejector as shown in Fig. 4. The difference based on the injection method seems to have affected the removal rate of PPCPs in sewage secondary treatment water. In contrast to these results, the substances that are difficult to remove using the ejector are DEET, ketoprofen, and levofloxacin, which are described below, which averaged $74.1 \%$ removal when the ejector was used, but $90.4 \%$ with microbubbles.

The 13 compounds found in PPCPs including atenolol, azithromycin, bezafibrate, caffeine, clarithromycin, crotamiton, DEET, ketoprofen, levofloxacin, metoprolol, propranolol, roxithromycin, sulpiride were treated below average in a low ozone-concentrated ejector process, with an average of $32.3 \%$. At high ozone concentrations, the average was $89.4 \%$. However, the aforementioned DEET, ketoprofen, and levofloxacin showed relatively low removal rates even at high concentrations, of $74.0 \%, 73.3 \%$, and $75.1 \%$, respectively. These showed a high removal rate (90.4\%) through the microbubble process. Among them, ketoprofen had the lowest removal rate of $73.3 \%$ and $81.9 \%$, respectively, for both processes, and in other papers has shown an $80 \%$ removal rate [29]. On the other hand, the UV process alone showed a removal rate of more than $90 \%$, so it was confirmed that the ozone treatment process was relatively poor due to differences caused by the ozonation mechanism [30].
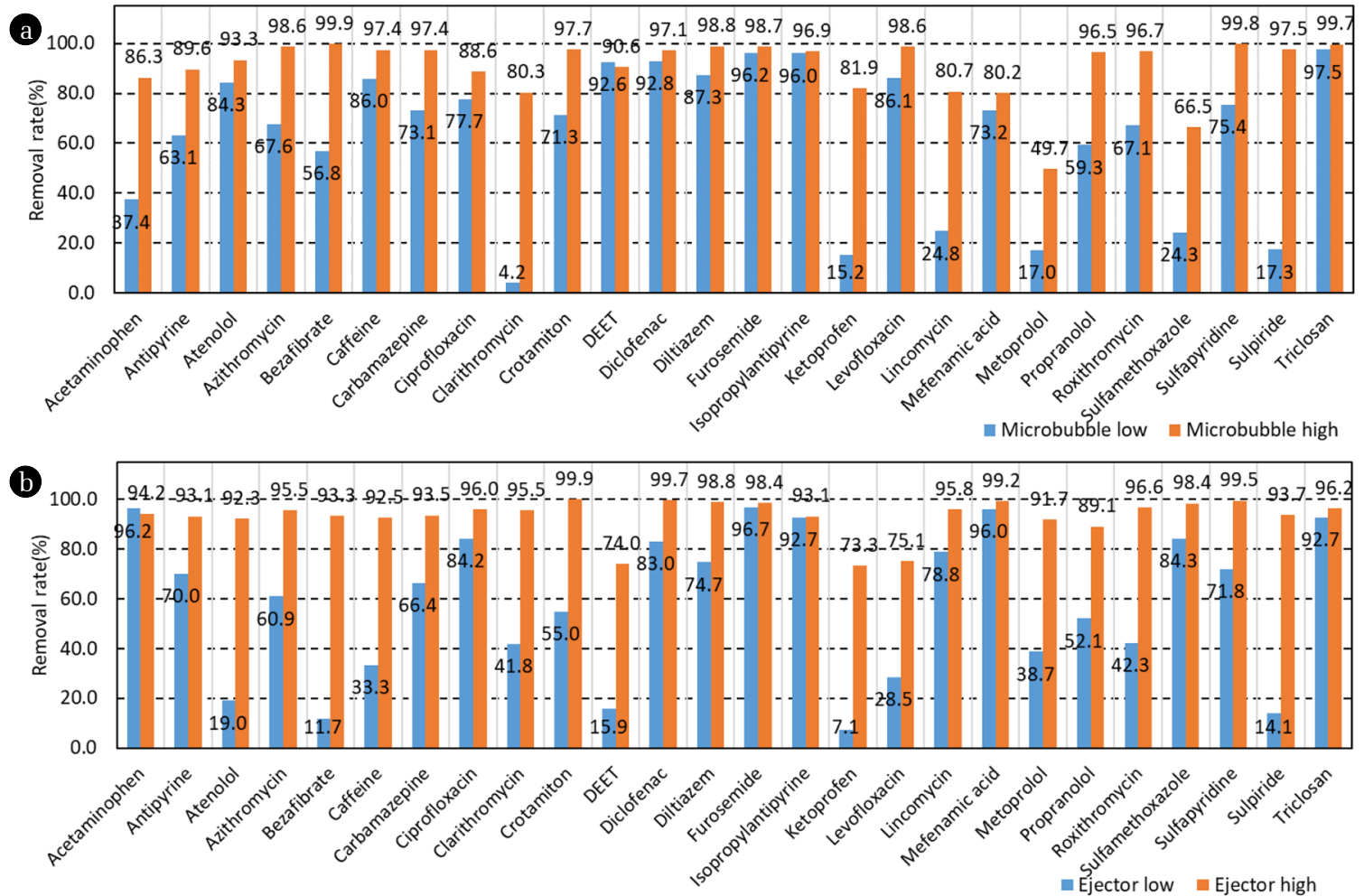

Fig. 4. Elimination efficiency by ozonation in ejector and microbubble. (a) Microbubble, (b) Ejector. 
There were 6 PPCPs, bezafibrate, clarithromycin, ketoprofen, metoprolol, propranolol, and sulpiride, which had a common low removal rate at low concentrations. These results are interpreted to be due to insufficient ozone injection, as a removal rate of $81.9 \%$ or more was achieved at higher concentrations, including removal of ketoprofen.

To compare the processing rates of each material of the microbubble and ejector at similar concentrations, the two treatment rates were divided into lines of slope 1 and illustrated in Fig. 5. The y-axis is the elimination rate achieved using the microbubbles, and the x-axis is the elimination rate achieved using the ejector. Therefore, if a PPCP is above the line, the processing rate in the microbubble process is high, and if it is below, it indicates that the PPCP was highly treated in the ejection process. The box in the upper-left area in Fig. 5(b) was enlarged in separate boxes also in the graph.

When a similar amount of ozone was injected at a low concentration, the average elimination efficiency of the ejector was $58.0 \%$, lower than that of the microbubble treatment (63.9\%). The two processes were compared, and 8 PPCPs in the ejector process and


Fig. 5. Elimination efficiency of ozone high injection in ejector and microbubble. (a) Low concentration, (b) High concentration.
18 PPCPs in the microbubble process were found to show a high elimination efficiency. Meanwhile, those that showed a higher elimination efficiency in the ejector process than the microbubble process include antipyrine, acetaminophen, clarithromycin, mefenamic acid, furosemide, lincomycin, metoprolol and sulfamethoxazole. When antipyrine and furosemide were excluded, the elimination efficiency difference was $41.2 \%$ on average, showing a difference of over 2 times, respectively.

When a similar amount of ozone was injected at a high concentration, the average elimination efficiency of the ejector was $93.0 \%$, slightly higher than that of the microbubble treatment (90.1\%). However, the number of PPCPs that showed a high elimination efficiency in the microbubble process was 16, higher than that in the ejector process. Those that showed a difference of over $10 \%$ were 6 PPCPs including antipyrine, ciprofloxacin, clarithromycin, lincomycin, mefenamic acid and sulfamethoxazole, and except ciprofloxacin the rest 5 PPCPs were found to show a big difference at the low concentration discussed above. However, unlike the low concentration, the difference in elimination efficiency was $24.7 \%$ on average, showing a lower difference. Those of which rank of elimination efficiency changed at the high concentration were ciprofloxacin. Its elimination efficiency in the microbubble process at the low concentration was higher by $4.4 \%$, but at the high concentration, its elimination efficiency in the ejector process was higher by $18.3 \%$.

Overall, more PPCPs showed a higher elimination efficiency in the microbubble process, but 8 PPCPs at the low concentration and 10 PPCPs at the high concentration showed a higher elimination efficiency in the ejector process. There were 6 PPCPs that showed a high elimination efficiency commonly in the ejector process including acetaminophen, clarithromycin, lincomycin, mefenamic acid, metoprolol and sulfamethoxazole.

The physicochemical properties kOW and pKa of the material indicate their affinity for water and whether they are dissociated according to $\mathrm{pH}$, respectively. In particular, hydrophilicity and degradation in the membrane filtration and oxidation process, as well as in the coagulation process, tend to be specifically related to the kOW and pKa of the micropollutants. In coagulation, the sulfamethoxazole was relatively well removed when kOW was lower and pKa was less than 7, as it was dissolved in water and showed ionicity $[7,19]$. In membrane filtration, the removal rate of materials with high solubility was low. The oxidation process showed low removal efficiency for hydrophobic substances [29].

Reviewing based on the physicochemical characteristics, the five species with higher removal rates using the ejector had kOW lower than 2 and pKa higher than 7, with the exception of clarithromycin and sulfamethoxazole. In other words, hydrophilic and hardly dissociated species had a higher removal rate in common at ejectors. Clarithromycin matched in one characteristic, which was higher pKa than 7 , and sulfamethoxazole had lower kOW than 2. With the exception of athenol and caffeine at low ozone concentrations, there was no compound showing a significantly higher removal rate with microbubble treatment among those with lower kOW lower than 2 and higher pKa than 7 as described above. Except for the above five species, the elimination rate of the rest was similar.

On the other hand, species with distinctly high removal rates 
under microbubble treatment, except for athenol and caffeine, had the opposite characteristics. That is, kOW was higher than 2 and pKa was lower than 7. Propranolol, however, had a high pKa.

The species which had low removal rate overall removal rate for both ozonation method were bezafibrate, clarithromycin, ketoprofen, mefenamic acid and sulpiride, and except for sulpiride, kOW was hydrophobic higher than 2 . This is consistent with the findings of the previous report [29], and is characteristic of the oxidation process that contrasts with the treatment pattern by membrane filtration. The hydrophobic and easily dissociated compound shows a high removal rate in membrane filtration, and the opposite properties are well treated in the oxidation process.

Summarizing the above characteristics, hydrophilic and hardly dissociated species generally had a high removal rate in the ejector, while opposite characteristics such as hydrophobic and well-dissociate species had a high removal rate from the microbubbles. In particular, the properties that are better removed in the oxidation process due to hydrophobic properties were better shown in the microbubble process.

\subsection{Inflection Point of Maximum Elimination Speed and Elimination Speed by PPCP}

The elimination trends of most PPCPs showed inflection points at different concentrations of ozone, rather than linear patterns. Since the concentration of injected ozone was constantly maintained over time, the value can be seen as elimination speed.

In terms of inflection point, PPCPs were divided, based on the time when a change in elimination speed was observed, into before and after inflection. Some PPCPs showed a high elimination speed before their inflection point, and some showed a high elimination speed after their inflection. In some PPCPs, no inflection point emerged.

Fig. S2 shows the maximum elimination speed of each PPCP based on the inflection point. Their elimination speed was mostly high at the low concentration of ozone, and 17 PPCPs in the ejector process and 9 PPCPs in the microbubble process showed a high elimination speed. However, out of top 14 PPCPs of which detected concentration was relatively high $(20 \mathrm{ng} / \mathrm{L}), 8$ PPCPs were from the ejector process and 6 PPCPs were from the microbubble process, showing a small difference.

Fig. 6 shows the maximum elimination speed observed before and after the inflection point compared to the initial concentration. Most PPCPs were proportional to their initial concentration, but some showed a higher or lower concentration than their initial concentration. At low concentrations of ozone, carbamazepine, diltiazem, lincomycin and triclosan were found to be high both in the ejector and microbubble processes, and bezafibrate and ketoprofen were low. Acetaminophen, isopropylantipyrine, mefenamic acid, furosemide and sulfapyridine were found to be high only when the ejector process was used, while caffeine, carbamazepine, crotamiton, levofloxacin, roxithromycin were high only with the microbubble process.

At high concentrations, most PPCPs were proportional to their initial concentration. While diclofenac, mefenamic acid, ketoprofen and lincomycin were found to show a higher elimination speed when the ejector process was used, crotamiton and lincomycin showed a relatively low elimination speed with the microbubble process.
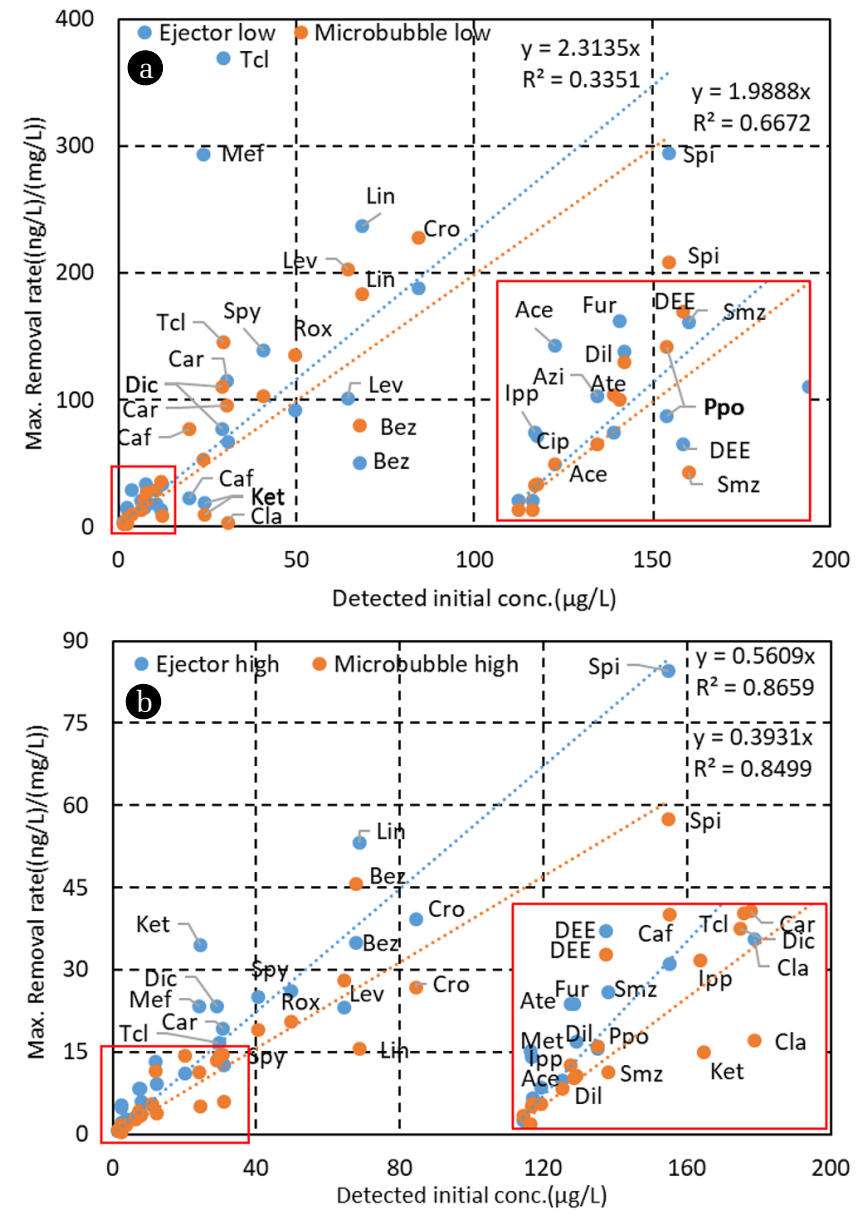

Fig. 6. Max elimination rate via initial concentration in 2ndary treated sewage. (a) Low concentration, (b) High concentration.

The slope of the ejector and microbubble processes was compared, and that of ejector was higher both at the low and high concentration. This can be attributed to the fact that the ozone dissolution concentration in the ejector process was higher than that in the microbubble process, while there was no significant difference in elimination rate at the low concentration, and even at the high concentration the rate was slightly higher than $90 \%$. Therefore, it does not seem to approach this study by the comparison of the performance of ejector and microbubble, but by elimination trends by PPCP in the next paragraph.

Table 1 shows the time when the inflection point of each PPCP emerged under 4 cases. Out of them, 3 cases showed similar trends. That is, their inflection point was observed within $4 \mathrm{~min}$, and their elimination speed was found to be high before the inflection point. Whereas, at the low concentration in the microbubble process, a different tendency was observed from the rest 3 cases. The number of PPCPs of which inflection point was observed after 5 min was 11, and 9 PPCPs showed a constant elimination speed. This can be attributed to the fact that the form of dissolved ozone and oxidation mechanism differ in the ejector and microbubble processes, and this seems to cause different elimination trends between PPCPs such as elimination rate and speed. 


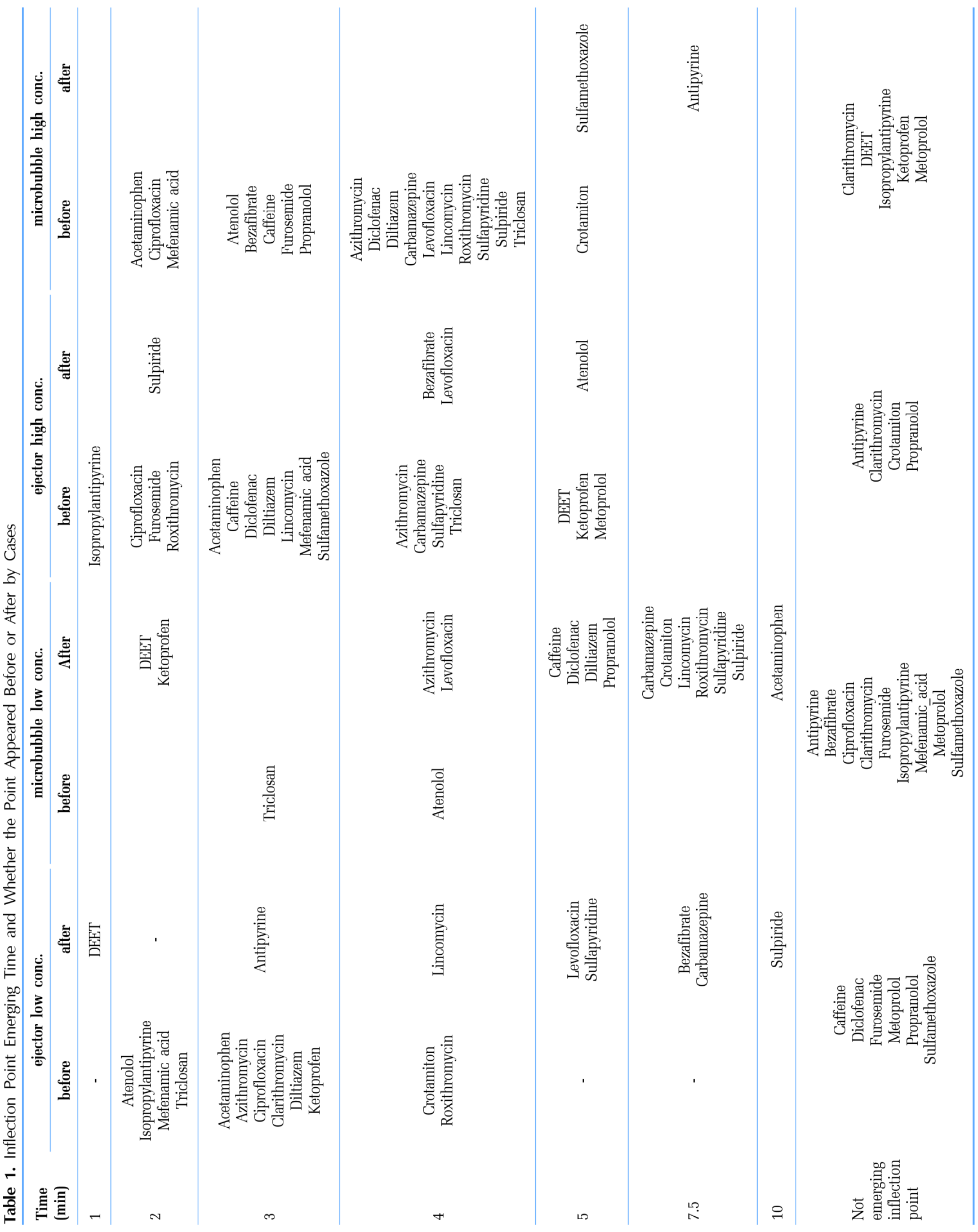


At the high concentration, most PPCPs showed a high elimination speed before the inflection point both in the ejector and microbubble processes. The number of PPCPs of which elimination speed was high after the inflection point was 4 in the ejector process and 2 in the microbubble process. In particular, in the microbubble process, the majority of the surveyed PPCPs (19 out of 26 PPCPs), showed the maximum speed before the inflection point emerged, and their inflection point was observed within 5 min.

\subsection{Toxicity Elimination}

Fig. 7 shows the results of the comparison of the concentration of PPCPs after being treated with ozone with the minimum toxic concentration discussed in Fig. 3 and Chapter 3.1. At low concentrations, the concentration of bezafibrate was found to be higher than the reference toxic concentration and therefore the toxicity of bezafibrate was not eliminated sufficiently in the low ejector process. A small amount of mefenamic acid and triclosan was detected under the reference toxic concentration in both processes. At the high concentration, a low level of bezafibrate was observed in both processes, which was also brought below the reference toxic concentration.
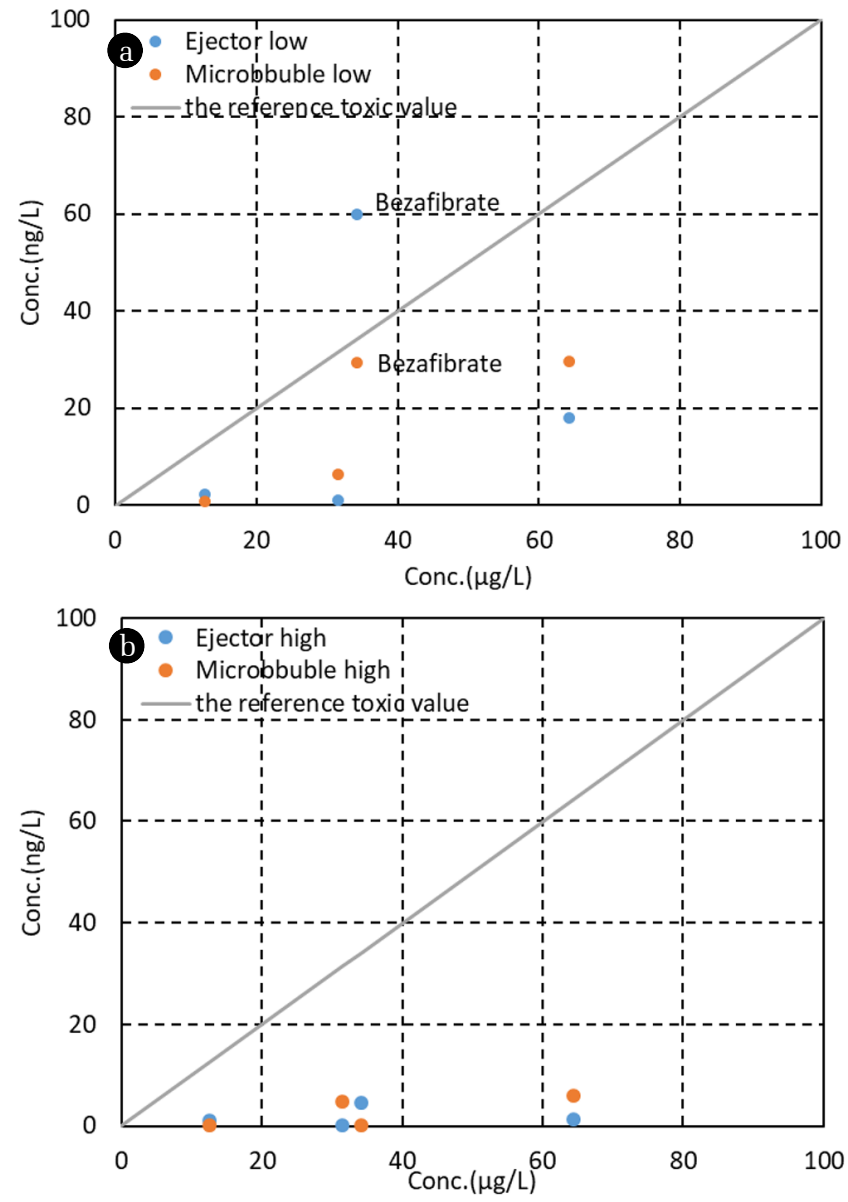

Fig. 7. Toxicity of PPCPs in 2ndary treated sewage water after treatment. (a) Low concentration, (b) High concentration.
In countries where TOC standards have been already introduced like South Korea, it will be necessary to apply a separate downstream process other than ozonation for eliminating TOC. Only with a single ozonation process, TOC cannot be eliminated sufficiently [12]. It is recommended to conduct studies on treating residual organics and TOC using methods like $\mathrm{OH}$ radical and adsorption.

\section{Conclusions}

The performance of microbubble and ejector was compared based on the elimination rate and trends of PPCPs in secondary treated sewage water.

1) Out of 59 reference PPCPs, 26 PPCPs including sulpride and crotaminton were detected.

2) The concentration of ozone dissolved using microbubbles was $4.0 \mathrm{mg} / \mathrm{L}$, and that using an ejector was $2.49 \mathrm{mg} / \mathrm{L}, 62.3 \%$ of the concentration in the microbubble process.

3) At the low concentration, the average elimination rate in the ejector and microbubble processes was $53.0 \%$ and $63.9 \%$, respectively, while the average elimination rate at the high concentration was similar. The number of PPCPs of which elimination rate was higher in the microbubble process was 18 at the low concentration and 16 at the high concentration, higher than the number in the ejector process (8 and 10 PPCPs, respectively).

4) Elimination speed showed different inflection points depending on the amount of injected ozone. The maximum elimination speed before and after the inflection point was compared, and ejector was found to be slightly higher. Most PPCPs showed their maximum elimination speed in the early stage of reaction before inflection, while 11 PPCPs were eliminated in the latter half of reaction at the low concentration in the microbubble process.

5) The results of a toxicity analysis using the reference toxic concentration based on a quantitative structure activity relationship (QSAR) model showed that the toxicity of both bezafibrate and triclosan was higher than the standard value. After treatment, only bezafibrate was not brought below the reference toxic concentration through the ejector process at a low concentration, and was reduced to a low concentration in the microbubble process. At the high concentration all PPCPs were reduced to below the reference toxic concentration through both the ejector and microbubble processes.

Ozone elimination trends of PPCPs in the microbubble and ejector processes were compared based on maximum elimination rate and toxicity, As a result, microbubble was found to be better, but its elimination trends differ by PPCP. Ozonation processes are eco-friendly, and their effects were also proved in this study. As TOC standards have been already introduced to Korea, it is expected to review the introduction of an additional process after secondary or tertiary processes in most sewage treatment plants. Single ozonation processes can control certain matters and toxicity, but there seem to be limits to complete detoxification or satisfaction of TOC standards. To introduce ozonation processes for this purpose, it will be necessary to consider measures to connect them with downstream processes. 


\section{Acknowledgments}

This work is supported by the Korea Institute of Civil Engineering and Building Technology, KICT, of Korean Government number 2021-0194.

This article was presented at IWA 11th Micropol \& Ecohazard Conference (2019) held on 20-24 October 2019 in Seoul, South Korea.

\section{Author Contributions}

I.K. (Research Fellow/Professor) conducted all the experiments and wrote the manuscript. J.L. (Senior Researcher) wrote and revised the manuscript.

\section{References}

1. Heberer T. Occurrence, fate, and removal of pharmaceutical residues in the aquatic environment: a review of recent research data. Toxicoletters 2002;131(1-2):5-17.

2. Nakada N, Shinohara H, Murata A, et al. Removal of selected pharmaceuticals and personal care products (PPCPs) and endocrine-disrupting chemicals (EDCs) during sand filtration and ozonation at a municipal sewage treatment plant. Water Res. 2007;41:4373-4382.

3. Kim JW. Fate of Pharmaceuticals and Personal Care Products in Waste Water Treatment Plants [dissertation]. Seoul: University of Seoul; 2013.

4. Kummerer K. Antibiotics in the aquatic environment - A review - Part I. Chemosphere 2009;75:417-434.

5. Kummerer K. Antibiotics in the aquatic environment - A review - Part II. Chemosphere 2009;75:435-441.

6. Kim SD, Cho J, Kim IS, Vanderford BJ, Snyder SA. Occurrence and removal of pharmaceuticals and endocrine disruptors in South Korean surface, drinking, and waste waters. Water Res. 2007;41:1013-1021.

7. Nam SW, Jo BI, Yoon Y, Zoh KD. Occurrence and removal of selected micropollutants in a water treatment plant. Chemosphere 2014;95:156-165.

8. Suárez S, Lema JM, Omil F. Pre-treatment of hospital wastewater by coagulation-flocculation and flotation. Bioresour. Technol. 2009;100:2138-2146

9. Snyder SA, Adham S, Redding AM, et al. Role of membranes and activated carbon in the removal of endocrine disruptors and pharmaceuticals. Desalination 2007;202:156-181.

10. Rossner A, Snyder SA, Knappe DR. Removal of emerging contaminants of concern by alternative adsorbents. Water Res. 2009;43:3787-3796.

11. Esplugas S, Bila D, Krause L, Dezotti M. Ozonation and advanced oxidation technologies to remove endocrine disrupting chemicals (EDCs) and pharmaceuticals and personal care products (PPCPs) in water effluents. J. Hazard. Mater. 2007;149:631-642.

12. Kim IH. Removal of Residual Pharmaceuticals in a Secondary Effluent from a Sewage Treatment Plant by Ozonation. J. Korean
Soc. Environ. Eng. 2018;40(12):487-494.

13. Lee C, Howe K, Thomson B. Ozone and biofiltration as an alternative to reverse osmosis for removing PPCPs and micropollutants from treated wastewater. Water Res. 2012;46:1005-1014.

14. Xu R, Zhang P, Wang Q, et al. Influences of multi influent matrices on the retention of PPCPs by nanofiltration membranes. Sep. Purif. Technol. 2019;212:299-306.

15. Eduardo MC, María FA, Carmen FG. Advanced Oxidation Processes for the Removal of Antibiotics from Water. An Overview. Water 2020;12(1):102-152

16. Xiong X, Wang B, Zhu W, Tian K, Zhang H. A Review on Ultrasonic Catalytic Microbubbles Ozonation Processes: Properties, Hydroxyl Radicals Generation Pathway and Potential in Application. Catalysits 2019;9(1):10-18.

17. Andinet T, Kim IH, Lee JY. Effect of microbubble generator operating parameters on oxygen transfer efficiency in water. Desalin. Water Treat. 2016;57:26327-26335.

18. WHO. World Health Organization. Guidelines for drinking-water quality. 4th ed. 2011.

19. Kim MK, Zoh KD. Occurrence and removals of micropollutants in water environment, Environ. Eng. Res. 2016;21(4):319-332.

20. Collier AC. Pharmaceutical contaminants in potable water: potential concerns for pregnant women and children. EcoHealth 2007;4:164-171.

21. Schriks M, Heringa MB, van der Kooi MM, de Voogt P, van Wezel AP. Toxicological relevance of emerging contaminants for drinking water quality. Water Res. 2010;44:461-476.

22. SCHER. Scientific Committee on Health and Environmental Risks. Chemicals and the water framework directive: draft environmental quality standards-diclofenac, ethinylestradiol, $17 \beta$ -estradiol. 2011.

23. WHO. World Health Organization. Pharmaceuticals in drinking-water. WHO/HSE/WSH/11.05. 2012.

24. Kim HJ, Kim SJ. Development of Prediction Method of Chronic NOEC using Deformity Phenomenon of Early Embryonic Developmental Stage of Danio rerio. Korean Soc. Biotechnol. Bioeng. J. 2019;34(4):306-316.

25. Dearden J. Prediction of Environmental Toxicity and Fate Using Quantitative Structure Activity Relationships (QSARs). J. Braz. Chem. Soc. 2002;13(6):754-762.

26. OECD. Overview of SAR for Environmental Endpoints, Contract \#EV5V-CT92-0211. 1995.

27. EPA. Chapter 6. Estimating Aquatic Toxicity Using ECOSAR, Sustainable Futures / P2 Framework Manual 2012. EPA-748B12-001 0-0.

28. Narumiya M, Simultaneous Quantification of PPCPs and their Fate in Municipal Wastewater Treatment Plants [dissertation]. Kyoto:Kyoto University; 2011.

29. Kang JS, Choi YH, Kwon SB, Yu YB. Assessment of Micro Organic Pollutants Removal Using Advanced Water Treatment Process and Nanofiltration Process. J. Kor. Soc. Environ. Eng. 2014;36(8):579-587.

30. Kim IH. Removal of Pharmaceuticals in Secondary Treated Wastewater with UV and UV/ $\mathrm{H}_{2} \mathrm{O}_{2}$ Treatment. J. Korean Soc. Civ. Eng. 2012;12(3):179-187. 